\title{
Causes and Effects of Delays in Constrution Projets
}

\author{
${ }^{1 *}$ Madan Kumar Sha, ${ }^{2}$ Padam Bahadur Shahi, ${ }^{3}$ Ramananda Pandit, \\ ${ }^{4}$ Ashok Pandey \\ ${ }^{l}$ PhD Scholar, School of Civil Engineering, Sai Nath University, Rachi, Jharkhand, India \\ ${ }^{2}$ Professor, Pokhara University, Nepal \\ ${ }^{3}$ PhD Scholar, Unique Star education Foundation (USEF), Dillibazar, Kathmandu, Nepal \\ ${ }^{4}$ Researcher, Public Health Research Society, Nepal (PHRSN), Chabahil 07, Kathmandu, Nepal
}

\begin{abstract}
Construction Projects are becoming complex due to cost overrun. This overrun sometimes results either in delay or incompletion or any other such difficulties. In Nepali construction industry traditional approach is predominantly in vogue in almost all of the projects. Identification of critical success factors will be helpful to formulate effective strategies for minimizing the cost of Construction Projects. The overall objective of the this research paper is 'To explore all the important factors contributing the cost overrun and identifying the critical factors of cause and effect of delay in construction project. Consultants and Contractors have been interviewed personally to get the practical problems through a survey questionnaire. The answers have been grouped and suitable methodologies for solving the problems have been formulated which are suitable for our Nepali Scenario. The results indicated that project modification must be needed with for reducing the timely completion. In particular, high level performance of the project managers, standard management practices, wide adoption of modern management tools, effective time and quality management, and techniques and team involvement in the project are found to be significant items for project management. There are six factors that affect delays in construction project which includes: time overruns cost overrun, dispute, arbitration, total abandonment; and litigation. The results of analysis shown time overrun and cost overrun were the two most common effects of delays in construction project.
\end{abstract}

Keywords: Cause; consultant; delay; effect; project

\section{Background}

The construction industry has great impact on economy of all countries (Assaf, Al-Khalil, \& Al-Hazmi, 1995). It is one of the sectors that provides crucial ingredient for the development of nations' economy (Alnuaimi \& Mohsin, 2013). During execution of construction projects, the works proceed at a slower pace than planned, and delays frequently appear. Their appearance leads to additional cost generation, conflicts among project participants.(Rahsid, Haq, \& Aslam, 2013) The construction industry in many countries accounts for 6-9 percent of the Gross Domestic Product (GDP) (Challal \& Tkiouat, 2012); and according to Bhimaraya, (2001), it reaches up to 10 percent of the GDP of most countries. The construction industry plays vital role in the economy growth and has a significant effect on the efficiency and productivity of other industry sectors. One cannot think of widespread investment in manufacturing, agriculture, or service sectors unless the construction results of infrastructure facilities are in place. In some of the developing countries, the growth rate of construction activity outstrips that of population and of GDP(Maurice Paul Okeyo, Charles Mallans Rambo, \& Paul Amollo Odundo, 2015).

Construction projects give rise to dissatisfaction to all the parties involved in the construction and the main role of the project manager is to make sure that the projects are completed within the allocated budget, time and cost achieving its quality specifications. Project implementation in Nepal has remained ineffective. Most development projects have failed to achieve the desired objectives. Time and cost overruns are common. The average delay in implementation of projects is about three years. It is eight years for energy projects, seven years for irrigation and transport projects(Agrawal, Subramanian, \& Kapoor, 2010). One of the most important projects in Nepalese's scenario is the 'Melamchi Water supply project'. The project was started in 2001 A.D. with intended completion in 2006 A.D. Because of slow progress, the due date was extended to 2007 and recently, the project has set a new target at 2013 A.D and now the completion is again postponed to September 2016. And nobody knows how much will be added to the original cost as a result of the extensions. The World Bank (WB) withdrew its investment from the project in 2005 A.D because of the delays. This project is not still completed. Due to alleged mismanagement and incompetence of those in charge of implementing the project, the deadline for its completion has already been extended twice (Melamchi, 2012). However, the delays in the project continue to occur. The main purpose of this study is to identify the delay factors and their impact (effect) on project completion. Earlier studies either considered the causes or the effects of project delays, separately. 
This study takes an integral approach and attempts to analyze the impact of causes on effects. Some causes and effects of delays in construction projects can be country-specific.(Alaryan, Elshahat, \& Dawood, 2014)

This research has identified major causes of delay and categorized them as client-related, contractorrelated, consultant-related, material-related, labor related, contract-related, contract relationship-related, and external factors. The study has also identified major effects of delay as: time overrun, cost overrun, dispute, arbitration, litigation, and total abandonment. Identification of causes and effects alone does not help the project managers to take appropriate remedial or preventive steps. The project managers need to understand, for example, what causes or factors result in time overrun or cost overrun. Therefore, the link between causes and effects of delays need to be established. Time overruns on infrastructure development projects during implementation continue to pose great challenges to developing countries.(Divya.R \& S.Ramya, 2015; Haseeb, Xinhai-Lu, Bibi, Maloof-ud-Dyian, \& Rabbani, 2011; Honrao \& Desai, 2015) Research has found that, there are many factors that impede on successful completion of projects on time, budget, and quality.(Pandey et al., 2015) This study sought to investigate on the factors that significantly contributed to time and cost overruns on construction projects. This evaluates relative ranking; and to quantify their impacts.(Pourrostam, 2010) The study was based on a questionnaire survey among persons drawn from contractors, consultants and client, involved in the implementation of the projects in the study.

\section{Research Objectives}

1. To identify the major causes of delays in construction project.

2. To identify the root sources of construction delay in construction projects in Nepal.

3. To identify the effects of delays in construction project

\section{Aspects on Mix Design}

The research has been structured as the case study of construction projects during implementation phase aspects of Kathmandu valley. The entire process revolves around the secondary data sources collected from the organization's periodic publications, yearly reviews, customer feedback charts and market analysis of the company in competition to the others with same business process design. The study is based on descriptive research design followed by analytical approach to achieve the objective of the study. In the study, the universe of the data (the population) was the pool of information collected through the available project document sources and was kept under rigorous methods under study. The data was clustered and extracted for reference rather than random selection of data without clustering. Certain web based information and old data sources for reference were purely taken on judgment with assumption of higher inclination with the study, but maintained to be for purely referential purposes to avoid deviation of the mean (in theoretical terms).

The collection of data for the proposed study was collected from various sources in tabulated and nontabulated (discretionary) forms. The sources of data gathered for the study were diverse and hence the study was based on the amount of information collected and tabulated from data sources as the organizational periodic publications, existing system design documents, market evaluation of the organization's products, customer feedback charts, progress charts, GANTT charts of the ongoing projects, PERT module depictions. The first beings were interviews with the representatives of the Construction Company and professionals working in the construction industry to collect the information. A questionnaire survey was conducted to obtain feedback from the construction industry. The collected data can be classified, depending on the sources and the accessibility as well as reliability of the sources, into two basic classifications: primary and secondary. The entire information gather are categorized as primary information. Next were the literature review to gather information about research topic and challenges faced by construction industry. It is obtained from the internet, articles in journals and papers and also some other published research book. From literature review, a clear framework of this research was established research work.

The data collection techniques followed during the process was best suitable with the circumstances prevalent and subjected to the restrictions of the regulations. They were: Personal interview of individuals of the organization under study, discussion with concerned authorities, onsite observations (non-participant), telephonic conversations, review of literatures (term-end analysis reports, long-term plan statements), Appraisals (success reviews, customer appraisals and feedbacks, project reviews) and assisting references (webbased information)

\section{Materials Used}

The developed survey questionnaire was distributed a fifty sets to the targeted respondent. About twenty tow sets were distributed to the contractors selected randomly from the list of "FCAN", Federation of Contractors' Association of Nepal and twenty eight sets were distributed to the consultants selected randomly from the list of "SCAEF", the Society of Consulting Architect and Engineer Federation, Nepal. The procedure used in analyzing of data was aimed at establishing the relative importance of the various factors that contribute 
to causes of delays, effects of delays, and methods of minimizing construction delays. There are three steps used in analyzing the data: calculating the relative importance index; ranking of factors in each category based on relative importance index, and to determine degree of correlation on ranking the factors among the two groups. The objective of conducting the analysis for this section is to establish the factors under the groups of causes identified from the literature review and the ranking according to their significant influence towards construction project delays. A ranking method was used to achieve this objective and the significant of using these methods is it can reveal the most influential factors within each category of causes.

\section{Results and Discussion}

A ranking method was used to achieve this objective and the significant of using these methods is it can reveal the most influential factors within each category of causes. A total fifty seven major factors that contributed to causes of delays were identified. The fifty seven factors were grouped into eight major groups: material related; labor-related; equipment-related; finance-related; contractor-related; client related; consultantrelated; and external factors. These factors were ranked in each group based on relative importance index from the viewpoint of contractor and consultant.

Factors of Material Related Delays

There are seven factors that contributed to the causes of delays related to material delays were identified and ranked from the viewpoint of contractors and consultants. The Spearman's Rank correlation coefficient, rho (rs) is 0.679 and has a significant value $(\mathrm{Z})$ of 0.094 .

Table 1: The result of factors of material delays

\begin{tabular}{|l|c|c|c|c|c|}
\hline \multirow{2}{*}{ Factors } & \multicolumn{2}{|c|}{ Consultant } & \multicolumn{2}{c|}{ Contractor } & Spearman's Rank coeff. Rho (rs) \\
\cline { 2 - 4 } & Index & Rank & Index & Rank & \multirow{2}{*}{$\begin{array}{c}\text { rs }=0.679 \mathrm{Z}=0.094 \text { Thus H0 is } \\
\text { accepted }\end{array}$} \\
\hline Shortage of construction materials & 4.2 & 1 & 4.24 & 1 & \\
\hline Late delivery of materials & 4.09 & 2 & 3.96 & 2 \\
\hline Imported of construction materials & 3.89 & 3 & 3.82 & 3 \\
\hline Poor procurement of construction materials & 3.85 & 4 & 3.6 & 4 \\
\hline Poor quality of construction materials & 3.7 & 5 & 3.73 & 5 \\
\hline Escalation of material prices & 3.57 & 6 & 3.71 & 6 \\
\hline Unreliable & 3.07 & 7 & 3.76 & 7 & \\
\end{tabular}

\section{Factors of Labor Related Delays}

There are seven factors of labor related delays were ranked based on relative importance index from the perspective of contractor and consultants. The results of analysis show that factor of labor productivity is the top most significant factor that contributed to causes of delays among seven factors of labor related delay. The ranking between two groups of respondent of this category has the Spearman's Rank correlation coefficient; rho (rs) is 0.893 and a significant value $(\mathrm{Z})$ of 0.007 . Thus the null hypothesis (Ho) is rejected and alternative hypothesis, $\mathrm{H} 1$ is accepted.

Table 2: The result of factors of labor related delays

\begin{tabular}{|l|c|c|c|c|c|}
\hline \multirow{2}{*}{ Factors } & \multicolumn{2}{|c|}{ Consultant } & \multicolumn{2}{c|}{ Contractor } & Spearman's Rank coeff. Rho (rs) \\
\cline { 2 - 5 } & Index & Rank & Index & Rank & rs $=0.893 \mathrm{Z}=0.007$ Thus rejected \\
Slow mobilization of labor & 3.86 & 4 & 3.76 & 5 \\
\hline Shortage of skill labor & 4.09 & 2 & 3.98 & 2 \\
\hline Labor productivity & 4.11 & 1 & 4.00 & 1 \\
\hline Labor supply & 4.00 & 3 & 3.89 & 3 \\
\hline Absenteeism & 3.09 & 7 & 3.71 & 6 \\
\hline Strike & 3.30 & 6 & 3.31 & 7 \\
\hline Low motivation/Morale & 3.35 & 5 & 3.76 & 4 & \\
\hline
\end{tabular}

\section{Factors of Equipment Related Delays}

Factors of causes of delays were ranked based on relative importance index from the viewpoint of contractor and consultant. Referring to this category has the Spearman's Rank correlation coefficient, rho (rs) is 0.764 and a significant value $(\mathrm{Z})$ is 0.046 . The null hypothesis, Ho is rejected and alternative hypothesis $\mathrm{H} 1$ is accepted. This shows that there is a significant degree of agreement between the ranking of the viewpoint of contractor and consultant. 
Table 3: The result of factors of equipment related delays

\begin{tabular}{|l|r|r|r|r|r|}
\hline \multirow{2}{*}{ Factors } & \multicolumn{2}{c|}{ Consultant } & \multicolumn{2}{c|}{ Contractor } & Spearman's Rank coeff. Rho (rs) \\
\cline { 2 - 5 } & \multicolumn{1}{|c|}{ Index } & \multicolumn{1}{c|}{ Rank } & \multicolumn{1}{c|}{ Index } & \multicolumn{1}{c|}{ Rank } & \multirow{2}{*}{$\begin{array}{r}\text { rs }=0.764 \mathrm{Z}=0.046 \text { Thus H0 is } \\
\text { accepted }\end{array}$} \\
\hline Insufficient number of equipments & 4.46 & 1 & 4.4 & 1 \\
\hline Frequent equipment breakdown & 4.33 & 2 & 4.18 & 2 \\
\hline Shortage of equipment part & 4.13 & 3 & 3.93 & 3 \\
\hline Improper equipment & 3.87 & 4 & 3.73 & 4 \\
\hline Slow mobilization of equipment & 3.85 & 5 & 3.76 & 5 \\
\hline Equipment allocation problem & 3.59 & 6 & 3.73 & 6 \\
\hline Inadequate modern Equipment & 3.3 & 7 & 3.76 & 7 & \\
\hline
\end{tabular}

\section{Factors of Finance Related Delays}

There are seven factors that contributed to the causes of delays related to finance were ranked based on relative importance index. The results of relative importance index and the ranking of factors of finance related delays between respondent of contractor and consultant. In this category, the null hypothesis, H0 is rejected and alternative hypothesis, H1 is accepted. The Spearman's Rank correlation coefficient, rho (rs) is 0.901 and has a significant value $(\mathrm{Z})$ of 0.006 . This value is much higher than $0.05(5 \%)$ which rejected the alternative hypothesis, $\mathrm{H} 1$ at a confidence level of $95 \%$. Therefore, concluded that there is significant degree of agreement in the ranking among the groups of respondents.

Table 4: The result of factors of finance related delays

\begin{tabular}{|l|c|c|c|c|c|}
\hline \multicolumn{1}{|c|}{ Factors } & \multicolumn{2}{c|}{ Consultant } & \multicolumn{2}{c|}{ Contractor } & Spearman's Rank coeff. Rho (rs) \\
\cline { 2 - 5 } & Index & Rank & Index & Rank & rs = 0.901 Z=0.006 Thus rejected \\
Ho & \\
\hline Inadequate fund allocation & 4.53 & 1 & 3.71 & 1 \\
\hline High interest rate & 4.27 & 2 & 4.04 & 2 \\
\hline Contractor's financial difficulties & 3.95 & 3 & 3.87 & 3 \\
\hline Unreasonable constraints to clients & 3.8 & 4 & 3.79 & 4 \\
\hline Delay payment to suppliers/subcontractors & 3.67 & 5 & 3.76 & 5 \\
\hline Monthly payment difficulties & 3.09 & 6 & 3.71 & 6 \\
\hline Client's financial difficulties & 3.02 & 7 & 4.29 & 7 & \\
\hline
\end{tabular}

\section{Factors of Contractor Related Delays}

The factors to causes of delays were ranked based on relative importance index between group of respondent of contractor and consultant. This category has the spearman's rank correlation coefficient, rho (rs) is 0.983 and a significant value $(\mathrm{Z})$ is 0.001 . The null hypothesis, Ho is rejected and alternative hypothesis $\mathrm{H} 1$ is accepted. This shows that there is a significant degree of agreement between the ranking of contractor and consultant.

Table 5: The result of factors of contractor related delays

\begin{tabular}{|c|c|c|c|c|c|}
\hline \multirow[t]{2}{*}{ Factors } & \multicolumn{2}{|c|}{ Consultant } & \multicolumn{2}{|c|}{ Contractor } & \multirow{3}{*}{$\begin{array}{c}\text { Spearman's Rank coeff. Rho (rs) } \\
\begin{array}{c}\text { rs }=0.983 \mathrm{Z} \\
=0.001 \text { Thus } \mathrm{H} 0 \text { is } \\
\text { rejected }\end{array}\end{array}$} \\
\hline & Index & Rank & Index & Rank & \\
\hline Inadequate contractor experience & 4.54 & 1 & 4.36 & 1 & \\
\hline Inappropriate construction methods & 4.39 & 2 & 4.22 & 2 & \\
\hline Inaccurate cost estimating & 4.29 & 4 & 4.23 & 4 & \\
\hline Poor site management and supervision & 4.26 & 5 & 4.23 & 5 & \\
\hline Improper project planning and scheduling & 4.23 & 6 & 4.16 & 6 & \\
\hline Unreliable subcontractor & 4.17 & 8 & 4.11 & 8 & \\
\hline Obsolete technology & 3.83 & 9 & 3.79 & 9 & \\
\hline
\end{tabular}

\section{Factors of Client Related Delays}

Both group of respondent agreed on the ranking of the factors based on relative importance index. The Spearman's Rank correlation, rho (rs) is 0.929 , and significant value $(Z)$ is 0.003 , which indicates a significant agreement in the ranking hence the null hypothesis, Ho is rejected and alternative hypothesis, H1 is accepted.

Table 6: The result of factors of client related delays

\begin{tabular}{|l|c|c|c|c|c|}
\hline \multirow{2}{*}{ Factors } & \multicolumn{2}{c|}{ Consultant } & \multicolumn{2}{c|}{ Contractor } & Spearman's Rank coeff. Rho (rs) \\
\cline { 2 - 5 } & Index & Rank & Index & Rank & \multirow{2}{*}{$\begin{array}{c}\text { rs }=0.929 \mathrm{Z}=0.003 \text { Thus H0 is } \\
\text { rejected }\end{array}$} \\
\hline Slow decision making by client & 4.39 & 1 & 4.32 & 1 & 2 \\
\hline Lack of experience & 4.02 & 2 & 3.8 & 3 \\
\hline Change orders & 3.96 & 3 & 3.87 & 3 \\
\hline Client interference & 3.92 & 4 & 3.78 & 4 \\
\hline Lack of capable representative & 3.85 & 5 & 3.76 & 5 \\
\hline Lack of communication and coordination & 3.48 & 6 & 3.73 & 6 \\
\hline Improper project feasibility study & 3.08 & 7 & 3.76 & 7 & \\
\hline DOI: 10.9790/1684-1402065258 & \multicolumn{2}{|c|}{ Www.iosrjournals.org } \\
\hline
\end{tabular}




\section{Factors of Consultant Related Delays}

The results of survey analysis of factors of consultant related delays. Factors of causes of delays were ranked based on relative importance index between respondents of contractor and consultant. This category has the Spearman's Rank correlation coefficient, rho (rs) is 0.928 and a significant value $(\mathrm{Z})$ is 0.008 . The null hypothesis, Ho is rejected and alternative hypothesis H1 is accepted. This shows that there is a significant degree of agreement between the ranking of contractor and consultant.

Table 7: The result of factors of consultant related delays

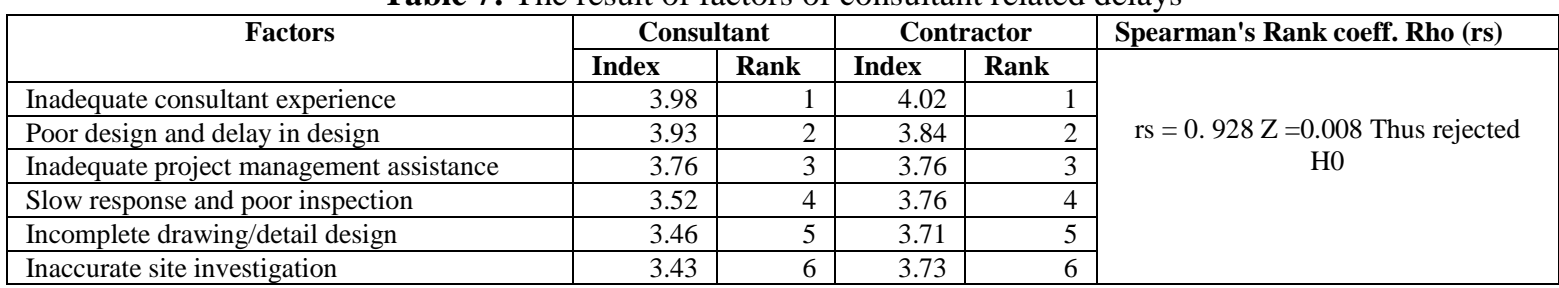

\section{Factors of External Related Delays}

There are seven factors of external related delays that contributed to the causes of delays were ranked based on relative importance index between contractor and consultant. The Spearman's Rank correlation coefficient, rho (rs) is 0.070 and significant value $(\mathrm{Z})$ is 0.882 which much greater than 0.005 . The null hypothesis, Ho is accepted and alternative hypothesis, H1 is rejected. This shows that there is no significant degree of agreement in the ranking between both contractor and consultant perspective.

Table 8: The result of factors of external related delays

\begin{tabular}{|c|c|c|c|c|c|}
\hline \multirow[t]{2}{*}{ Factors } & \multicolumn{2}{|c|}{ Consultant } & \multicolumn{2}{|c|}{ Contractor } & Spearman's Rank coeff. Rho (rs) \\
\hline & Index & Rank & Index & Rank & \multirow{8}{*}{$\begin{array}{c}\mathrm{rs}=0.070 \mathrm{Z}=0.882 \text { Thus } \mathrm{H} 0 \text { is } \\
\text { accepted }\end{array}$} \\
\hline Unforeseen ground condition & 4.07 & 1 & 3.91 & 1 & \\
\hline Unexpected geological condition & 3.83 & 2 & 3.73 & 2 & \\
\hline Inflation/prices fluctuation & 3.83 & 3 & 3.71 & 3 & \\
\hline Sloe site clearance & 3.8 & 4 & 3.73 & 4 & \\
\hline Problem with neighbors & 3.76 & 5 & 3.73 & 5 & \\
\hline Weather condition & 3.57 & 6 & 3.76 & 6 & \\
\hline Conflict, War and public enemy & 3.17 & 7 & 3.73 & 7 & \\
\hline
\end{tabular}

\section{Identification of the Major Causes of Delays}

During a construction project, delays may result from many circumstances. In this research, based on data analyzed earlier, a total of fifty seven factors to causes of delays were grouped into eight groups of causes of delays in construction project. In order to identify the major delays groups or the major causes of delays, the group that causes delays was ranked based on mean value (the average indexes) between two group of respondent contractors and consultants. The following is a brief discussion of the groups to causes of delays according to the ranking of major delays groups.

Table 9: Ranking of major delays groups

\begin{tabular}{llcccccc}
\hline \multirow{2}{*}{ No. } & Groups & Consultant & & Contractor & \multicolumn{2}{c}{ Overall } \\
\cline { 3 - 7 } & & Mean & Rank & Mean & Rank & Mean & Rank \\
\hline $\mathbf{1}$ & Contractor & 4.12 & 1 & 4.05 & 1 & 4.09 & 1 \\
$\mathbf{2}$ & Equipment & 3.93 & 2 & 3.92 & 2 & 3.93 \\
$\mathbf{3}$ & Client & 3.92 & 3 & 3.85 & 3 & 3.89 & 3 \\
$\mathbf{7}$ & External & 3.72 & 5 & 3.84 & 4 & 3.80 & 4 \\
$\mathbf{4}$ & Material & 3.76 & 4 & 3.83 & 5 & 3.77 & 5 \\
$\mathbf{5}$ & Finance & 3.7 & 6 & 3.8 & 6 & 3.74 & 6 \\
$\mathbf{6}$ & Consultant & 3.68 & 7 & 3.76 & 7 & 3.74 & 7 \\
$\mathbf{8}$ & Labor & 3.68 & 8 & 3.76 & 8 & 3.71 \\
\hline
\end{tabular}

\section{The Common Effects of Delays}

In order to identify the effect of delays in construction project, there are six factors that effects delays were identified and ranked based on the mean value. Results shows that time overruns and cost overrun were the two most common effects of delays in construction project from the view of point of contractor and consultant. 
Table 10: Ranking the common effects of delays

\begin{tabular}{|c|c|c|c|c|c|}
\hline \multirow[t]{2}{*}{ No. } & \multirow[t]{2}{*}{ Effects of Delay } & Consultant & Contractor & \multirow[b]{2}{*}{ Mean } & \multirow[b]{2}{*}{ Rank } \\
\hline & & Index & Index & & \\
\hline 2 & Cost overrun & 2.54 & 2.76 & 2.65 & 2 \\
\hline 4 & Total abandonment & 1.98 & 1.2 & 1.59 & 4 \\
\hline 5 & Arbitration & 1.04 & 1.02 & 1.04 & 5 \\
\hline 6 & Litigation & 1.02 & 1.01 & 1.02 & 6 \\
\hline
\end{tabular}

The major delays groups were identified and ranked, which group of contractor related delays is the top main groups that contribute to the causes of delays. From a total of fifty seven factors to causes of delays, twenty top most important factors have been identified. The top five most important factors that contributed to the causes of delays are factors of insufficient numbers of equipment, inaccurate time estimate, monthly payment difficulties, change orders, and inaccurate cost estimate. The effects of delays have been identified which time overrun and cost overrun were the most common effects of delays in construction projects. To minimize delays in construction project have been identified the top fifteen effective methods of minimizing construction delays from a total of thirty five methods.

\section{Conclusions}

There are three objectives of this study which have been achieved. The first objective was to identify the major causes of delays, the effects of delays, and the methods of minimizing delays in construction projects. Therefore, concluded that there is a significant degree of agreement between the two groups with respect to their ranking. This shows that the labor productivity has significant effect on the construction delay. The first objective of the study has been successfully identified. A total of fifty seven factors that causes delays were identified. Some of these factors were the top ten most important factors that contributed to the causes of delays includes: insufficient numbers of equipment; inaccurate time estimate; monthly payment difficulties; changes orders; inaccurate cost estimate; poor site management and supervision; inadequate modern equipment; shortage of construction materials; incompetent project team; improper project planning and scheduling; and contractor's financial difficulties. The factors were grouped into eight groups of causes of delays. Group of contractorrelated delays was ranked the most significant groups that cause delays, followed by group of equipment-related delay, client related delays, material-related delays, finance-related delays, consultant-related delays, externalrelated delays, and labor related delays. The second objective of this research was to identify the common effects of delays in construction project. This objective has been successfully achieved. There are six factors that affect delays in construction project which includes: time overruns cost overrun, dispute, arbitration, total abandonment; and litigation. The results of analysis shown time overrun and cost overrun were the two most common effects of delays in construction project.

\section{Recommendation}

From this study, some recommendations are given as follows:

(1) Construction project delays caused by contractors are due mainly to the low technical and managerial skills of contractors in developing countries. In order to improve contractors' managerial skills there is a need for continuous work-training programs for personnel in the industry to update their knowledge and be familiar with project management techniques and processes.

(2) Delays in construction projects can be reduced through the joint efforts of participants in the construction industry. Clients, designers/consultants, contractors, suppliers, finance sources, educational institutions, manufacturers, and the government should cooperate to provide the infrastructure necessary for efficient management. A means of achieving this is to formulate and execute a participatory program for the development of the construction industry through a dedicated national agency.

(3) All parties involved in project agreed that delay occurs mostly during the construction phase. Therefore, in resolving those problems, suggestion to increase construction productivity, followed by enhancing the expertise and skill of human resources, and conducted site meetings more frequently. A strategic view of solving delay problems should be considered as an importance of management aspects, the effects of knowledge and information flow between the organization levels, and importance of top management contribution in solving the problems.

(4) Modern construction equipments reduce the human labor that increasing the capacity of the company to accomplish the task within the targeted time frame. Thus, productivity can be enhanced by using the modern equipments with reduced accidents and conflict.

(5) Proper project plan should be prepared before implementing the project. The project plan serves as a blue print or a road map for the measurement of the work performed at different phases of the construction. 
(6) Project schedule are to be set in a realistic manner. Fake or manipulated project schedule may lead to either earlier than estimated or delayed than expected. Thus arise conflict which is itself a vital factor for the delay of construction work at implementation phase.

\section{References}

[1]. Agrawal, S., Subramanian, S., \& Kapoor, S. (2010). Operations Research-Contemporary Role in Managerial Decision Making. Int. J. Res. Rev. Appl. Sci., 3(May), 200-208. Retrieved from http://arpapress.com/Volumes/Vol3Issue2/IJRRAS_3_2_10.pdf

[2]. Alaryan, A., Elshahat, A., \& Dawood, M. (2014). Causes and Effects of Change Orders on Construction Projects in Kuwait, 4(6), $1-8$.

[3]. Alnuaimi, A. S., \& Mohsin, M. a Al. (2013). Causes of Delay in Completion of Construction Projects in Oman. International Conference on Innovations in Engineering and Technology (ICIET'2013), 99231200, 267-270. doi:10.15242/IIE.E1213590

[4]. Assaf, S. a., Al-Khalil, M., \& Al-Hazmi, M. (1995). Causes of Delay in Large Building Construction Projects. Journal of Management in Engineering, 11(11), 45-50. doi:10.1061/(ASCE)0742-597X(1995)11:2(45)

[5]. Challal, A., \& Tkiouat, M. (2012). Identification of the Causes of Deadline Slippage in Construction Projects: State of the Art and Application. Journal of Service Science and Management, 05(June), 151-159. doi:10.4236/jssm.2012.52019

[6]. Divya.R, \& S.Ramya. (2015). Causes, Effects And Method Of Minimizing Delays In Construction Projects. National Conference on Research Advances in Communication, Computation, Electrical Science and Structures, 47-53.

[7]. Haseeb, M., Xinhai-Lu, Bibi, A., Maloof-ud-Dyian, \& Rabbani, W. (2011). Problems of Projects and Effects of Delays in the Construction Industry of Pakistan. Australian Journal of Business and Management Research, 1(5), 41-50.

[8]. Honrao, M. Y., \& Desai, P. D. B. (2015). Study of Delay in Execution of Infrastructure Projects -, 5(6), 1-8.

[9]. Maurice Paul Okeyo, Charles Mallans Rambo, \& Paul Amollo Odundo. (2015). Effects of Delayed Payment of Contractors on the Completion of Infrastructural Projects: A Case of Sondu-Miriu Hydropower Project, Kisumu County, Kenya. Chinese Business Review, 14(7), 325-336. doi:10.17265/1537-1506/2015.07.001

[10]. Melamchi. (2012). Melamchi Water Supply Project, (10), 86-87.

[11]. Pandey, A., Umashankar, S., Dai, H., Pandit, C., Kunwar, M., Pandey, M., \& Rai, N. (2015). Assessing Health Education Techniques in Enhancing the Knowledge of HIV/AIDS among Adolescents. International STD Research \& Reviews, 3(1), 1-7. doi:10.9734/ISRR/2015/10961

[12]. Pourrostam, T. (2010). Causes and Effects of Delay in Iranian Construction Projects, (5), 291-295.

[13]. Rahsid, Y., Haq, S., \& Aslam, M. S. (2013). Causes of Delay in Construction Projects of Punjab-Pakistan : An Empirical Study. Journal of Basic and Applied Scientific Research, 3(4), 87-96. doi:10.5829/idosi.hssj.2013.8.1.1128 